\title{
A Multicompartment Liver-Based Pharmacokinetic Model for Benzene and Its Metabolites in Mice
}

\author{
Cammey E. Cole ${ }^{1}$, Paul M. Schlosser ${ }^{2,3}$, and Hien T. Tran ${ }^{3,4}$ \\ ${ }^{1}$ Department of Mathematics and Computer Science, Meredith College, Raleigh, N.C. \\ ${ }^{2}$ CIIT Centers for Health Research, Research Triangle Park, N.C. \\ ${ }^{3}$ Center for Research in Scientific Computation, North Carolina State University, Raleigh, N.C. \\ ${ }^{4}$ Department of Mathematics, North Carolina State University, Raleigh, N.C.
}

May 23, 2002

\begin{abstract}
Benzene is a highly flammable, colorless liquid, and ubiquitous exposures result from its presence in gasoline vapors, cigarette smoke, and industrial processes. After uptake into the body, benzene undergoes a series of metabolic transformations resulting in multiple metabolites that exert toxic effects on the bone marrow. We developed a physiologically based pharmacokinetic model for the uptake and elimination of benzene in mice to relate the concentration of inhaled and orally administered benzene to the tissue doses of benzene and its key metabolites. This model takes into account the zonal distribution of enzymes and metabolisms in the liver, rather than treating the liver as one homogeneous compartment, and considers metabolism in tissues other than the liver. Analysis was done to examine the existence and uniqueness of solutions of the system. We then formulated an inverse problem to obtain estimates for the unknown parameters; data from multiple laboratories and experiments were used. Despite the sources of variability, the model simulations matched the data reasonably well in most cases, showing that the multicompartment metabolism model does improve predictions over the previous model [6] and that in vitro metabolic constants can be successfully extrapolated to predict in vivo data for benzene metabolism and dosimetry.
\end{abstract}

\section{Introduction and Problem Motivation}

Benzene is an ubiquitous environmental pollutant and is a component of both cigarette smoke and automobile emissions [37, 38]. It has also been a widely used solvent and a precursor for many synthetic materials [14]. Benzene causes leukemia in humans when they are exposed to high doses for extended periods; however, leukemia risks in humans at low exposures are uncertain. Chronic exposures to benzene result in a variety of blood and bone marrow disorders in both humans and laboratory animals $[9,18]$. Increased incidence of acute myelogenous leukemia in humans resulted from high-level benzene exposures. Although the leukemogenicity of benzene has not been proven in rats or mice, benzene has been demonstrated to induce solid tumors in those species [20, 21]. 
Most metabolism of benzene occurs in the liver; enzymes capable of metabolizing benzene are also present in the lungs and kidneys of rodents and in the bone marrow of some rodent species $[2,5]$. The initial metabolite of benzene is benzene oxide. Benzene oxide rearranges spontaneously to form phenol. Phenol is subsequently hydroxylated to form hydroquinone and catechol as well as 1,2,4-benzenetriol [16, 38].

Much research has been done through the years on benzene dosimetry in rodents. Physiologically based pharmacokinetic (PBPK) modeling seeks to incorporate known physiological parameters such as body weight, organ volumes, and blood flow rates in particular tissues, as well as known partition coefficients that have been obtained through experimentation. The model described here extends a previous model that predicted tissue concentrations of certain metabolites in vivo in mice as a function of exposure using metabolic parameters obtained in vitro. In this paper, we consider metabolism in tissues other than the liver and additionally look at the zonal distribution of enzymes and metabolism in the liver, rather than assuming the liver to be one homogeneous compartment. Certain enzymes are found only in certain zones of the liver; we know that enzyme-mediated metabolism can occur only in the zones where the associated enzymes are present. Thus, to be physiologically correct the liver can not be considered as a single homogeneous compartment. The objective of this study was to improve and further develop a PBPK model that predicts tissue concentrations of certain metabolites in mice based on exposure using metabolic parameters obtained in vitro. Since in vitro metabolic parameters are also available for humans, the model could then be extrapolated to humans for risk assessment.

The organization of the paper is as follows. We begin in Section 2 with the development of the model from mass balance techniques and incorporate specific metabolic equations for benzene. Section 3 examines the existence and uniqueness of solutions of the system. Section 4 deals with parameter estimation through an inverse problem formulation using a modified maximum likelihood function. Numerical results are discussed in Section 5. Section 6 contains concluding remarks.

\section{Model Development}

The structure of the PBPK model used in this study is depicted in Figure 1. To the extent possible, metabolic parameters have been estimated from previously published in vitro work. The basic structure of the model is the same as presented by Cole et al. [6]; for the remainder of this article, the previous model will be referred to as the Single Compartment Liver (SCL) model. Parameters have been scaled by the protein concentrations in liver and kidney to model in vivo metabolism. Physiological parameters, specifically tissue volumes and blood flows, were also taken from the open literature. In addition, a list of abbreviations and symbols used in the model can be found in Appendix A.

\subsection{Model Structure and Assumptions}

The model tracks systemic and tissue levels of benzene, benzene oxide, phenol, and hydroquinone, as well as the total amounts of muconic acid, phenylmercapturic acid, phenol conjugates, hydroquinone conjugates, and total catechol and trihydroxy benzene (plus conju- 
gates) produced. For benzene, benzene oxide, phenol, and hydroquinone, the body is divided into the following compartments: blood (except for benzene); kidney; liver; fat; rapidly perfused tissues, which consist of brain, heart, spleen, intestines, and bone marrow; and slowly perfused tissues, which contain muscle and skin. The liver is further subdivided into three compartments of equal volume which represent the three zones of the liver (see discussion later in this section). This is the same basic compartment structure as the SCL model except that the liver has been divided into multiple compartments and a separate kidney compartment has been added. Previously, the kidney had been considered to be part of the rapidly perfused tissue compartment. Additionally, nonenzymatic metabolism is assumed to occur in all tissues.

A stomach lumen compartment and alveolar gas-exchange region were also included for benzene to describe oral and inhalation exposures, respectively, as was done in the SCL model. For benzene oxide, phenol, and hydroquinone, separate differential equations were used for the blood compartment, rather than the usual pseudo-steady-state assumption. All metabolites that are represented individually as a single compartment are assumed to be the amount of the metabolite in the urine, that is, a single equation is used to represent the amount of the metabolite excreted in the urine. All compartments are assumed to be well-mixed.

As before, the venous-equilibrium model was used for each tissue compartment; that is, the concentration in the venous blood leaving the compartment was assumed to be at equilibrium with the concentration in the compartment, with $P_{j}^{i}$ being the equilibrium partition coefficient for chemical $i$ in tissue $j$ :

$$
C V_{j}^{i}=\frac{C_{j}^{i}}{P_{j}^{i}}
$$

The total cardiac flow is modeled as the sum of flows to each tissue compartment:

$$
Q_{\text {Card }}=Q_{F}+Q_{S}+Q_{R}+Q_{L}+Q_{K}
$$

The concentration of benzene in the mixed venous blood is given by:

$$
C V^{B Z}=\frac{C V_{F}^{B Z} Q_{F}+C V_{S}^{B Z} Q_{S}+C V_{R}^{B Z} Q_{R}+C V_{L}^{B Z} Q_{L}+C V_{K}^{B Z} Q_{K}}{Q_{\text {Card }}} .
$$

Since the blood:air partition coefficient for benzene is relatively low $\left(P_{B l: A i r}^{B Z}=18\right)[23]$, a standard pseudo-steady-state gas-exchange equation is used to describe benzene concentration in arterial blood:

$$
C A^{B Z}=\frac{Q_{A v V} C_{I}^{B Z}+Q_{C a r d} C V^{B Z}}{\frac{Q_{A v V}}{P_{B l: A i r}}+Q_{C a r d}} .
$$

(For high partition coefficient values $(\geq 100)$, this relation is not correct because the concentration reaching the gas exchange region is significantly less than the inhaled concentration.)

We assumed that the uptake of orally administered benzene in the body is from the stomach to the liver, where it can be metabolized or distributed to the rest of the body. We also assumed that this is a one-way exchange; once benzene is taken up by the liver it does not return to the stomach lumen. This uptake is represented by a linear equation:

$$
k_{8} A M^{\text {Stom }} \text {. }
$$


This model considers metabolism in tissue other than the liver and incorporates information about the particular zone of the liver in which metabolism occurs (see Figure 2). Multiple studies have been done to confirm the heterogeneous nature of the liver $[1,8,12,24,25]$. It is noted that the zones of the liver differ in their enzyme composition. The oxygen and nutrient contents are also thought to be of varying quality in each zone, which correspond in rank to the zone numbering [12].

According to Medinsky et al. [25], P450 2E1 (CYP2E1) is found primarily in the pericentral hepatocytes, or zone 3, of the liver. Therefore, when the liver was subdivided, metabolism mediated by CYP2E1 was only considered to occur in zone 3 of the liver. Rate equations taken from Lovern et al. [17] for the oxidation of benzene to benzene oxide, phenol to hydroquinone and catechol, and hydroquinone to trihydroxy benzene have been modified to show the metabolism confined to the third zone:

$$
\begin{aligned}
R M_{B O, L 3}^{B Z} & =k_{1} \frac{V_{2 E 1} C_{L 3}^{B Z}}{D_{L}} C^{M P} \frac{T_{L}}{3} \\
R M_{H Q, L 3}^{P H} & =k_{5} \frac{V_{2 E 1} C_{L 3}^{P H}}{D_{L}} C^{M P} \frac{T_{L}}{3} \\
R M_{C a t, L 3}^{P H} & =k_{6} \frac{V_{2 E 1} C_{L 3}^{P H}}{D_{L}} C^{M P} \frac{T_{L}}{3} \\
R M_{T H B, L 3}^{H Q} & =k_{7} \frac{V_{2 E 1} C_{L 3}^{H Q}}{D_{L}} C^{M P} \frac{T_{L}}{3},
\end{aligned}
$$

where $V_{2 E 1}$ is the activity of CYP2E1 per milligram of cytosolic protein from whole liver homogenates as determined by the oxidation of p-nitrophenol to p-nitrocatechol, $C^{M P}$ is the amount of microsomal protein per gram of liver, and

$$
D_{L}=1+A^{B Z} C_{L 3}^{B Z}+A^{P H} C_{L 3}^{P H}+A^{H Q} C_{L 3}^{H Q} .
$$

Unlike in the previous SCL model where $C^{M P}$ was estimated, the value of $C^{M P}$ found by Medinsky et al. [26] was used. The kidney contains approximately $10 \%$ of the concentration of CYP2E1 found in the liver [7]. So, it is assumed that relative to the metabolism in the liver, $10 \%$ of the metabolism mediated by CYP2E1 is in the kidney. The $V_{2 E 1}$ is scaled by $10 \%$ to give us the rate equations for the metabolisms using CYP2E1 in the kidney:

$$
\begin{aligned}
R M_{B O, K}^{B Z} & =k_{1} \frac{V_{2 E 1}}{10} \frac{C_{K}^{B Z}}{D_{K}} C^{M P} T_{K} \\
R M_{H Q, K}^{P H} & =k_{5} \frac{V_{2 E 1}}{10} \frac{C_{K}^{P H}}{D_{K}} C^{M P} T_{K} \\
R M_{C a t, K}^{P H} & =k_{6} \frac{V_{2 E 1}}{10} \frac{C_{K}^{P H}}{D_{K}} C^{M P} T_{K} \\
R M_{T H B, K}^{H Q} & =k_{7} \frac{V_{2 E 1}}{10} \frac{C_{K}^{H Q}}{D_{K}} C^{M P} T_{K}
\end{aligned}
$$

where

$$
D_{K}=1+A^{B Z} C_{K}^{B Z}+A^{P H} C_{K}^{P H}+A^{H Q} C_{K}^{H Q} .
$$


$A^{B Z}$ was found by taking the inverse of the average of the $K_{m}$ found by Nedelcheva et al. [27]; other rate parameters were taken from Lovern et al. [17]. $T_{L}$ is the total mass of the liver and $T_{K}$ is the total mass of the kidney. We assumed that tissue has the same density as water; thus,

$$
T_{j}=V_{j} * \frac{10^{3} g}{1 L}
$$

where $j$ could be the liver $(\mathrm{L})$ or the kidney $(\mathrm{K})$.

Since the metabolism of benzene oxide to phenol is nonenzymatic, it is assumed that this metabolism occurs in all compartments and is represented by the first-order equation:

$$
R M_{P H, j}^{B O}=k_{2} C_{j}^{B O} V_{j}
$$

where $j$ is the compartment index.

Glutathione S-transferase is required for the metabolism of benzene oxide to phenylmercapturic acid. It is found in tissue such as the liver, kidney, muscle, and heart [13]. Within the liver, glutathione S-transferase is found primarily in the plate limiting hepatocytes of the central vein [19]. Thus, we consider first-order metabolism to occur in the slowly and rapidly perfused tissues, the fat, the kidney, the blood, and the third zone of the liver, represented by the equation:

$$
R M_{P M A, j}^{B O}=k_{3} C_{j}^{B O} V_{j}
$$

where $j$ is the compartment index.

The rate of metabolism of benzene oxide to muconic acid is assumed to be first-order, as in the previous model. Epoxide hydrolase, which mediates this metabolism, is found in the centrilobular region (zone 3) of the liver [29]. Thus, the rate equation becomes

$$
R M_{M A, L 3}^{B O}=k_{4} C_{L 3}^{B O} \frac{V_{L}}{3}
$$

The parameter $k_{2}$ was obtained from work by Lovern et al. [17]; $k_{3}$ and $k_{4}$ were not available from the literature and were estimated in this study.

As in the SCL model, the assumption on the grouping of sulfation and glucuronidation is applied in this model as well. Since sulfation takes place primarily in zone 1 of the liver, the rate equation for the conjugation of phenol from Seaton et al. [35] was used with the metabolism only occurring in zone 1 :

$$
R M_{C o n j, L 1}^{P H}=\left(\frac{V_{P H 1} C_{L 1}^{P H}}{K_{m, 1}^{P H}+C_{L 1}^{P H}}+\frac{V_{P H 2} C_{L 1}^{P H}}{K_{m, 2}^{P H}+C_{L 1}^{P H}}\right) C^{C P} \frac{T_{L}}{3} .
$$

The $K_{m, 1}^{P H}$ and $K_{m, 2}^{P H}$ found by Seaton et al. [35] in their in intro studies were used. The value of $C^{C P}$ obtained by Medinsky et al. [26] was used.

The metabolism of hydroquinone to its conjugates is assumed occur in zone 3 since the glucuronidation capacity is greater in this region [25]. This metabolism is represented by the equation for glucuronidation from Seaton et al. [35]:

$$
R M_{C o n j, L 3}^{H Q}=\frac{V_{H Q} C_{L 3}^{H Q}}{K_{m}^{H Q}+C_{L 3}^{H Q}} C^{M P} \frac{T_{L}}{3} .
$$


Again, the value for $K_{m}^{H Q}$ was taken from the in vitro work of Seaton et al. [35].

As in the SCL model, it is assumed that part of the administered benzene binds to tissue macromoles, which is why Parke and Williams [28] observed that part of the administered benzene was still found in the tissues of rabbits two days after dosing and only 80-90\% of the administered dose was found in the excreta. Therefore a binding term was considered for phenol and hydroquinone.

All parameter values taken from the literature are listed in Table 1.

\subsection{Partition Coefficients}

The only partition coefficients between various tissues and blood that were available from the literature were for benzene. This model requires partition coefficients between various tissues and blood for benzene oxide, phenol, and hydroquinone as well. The partition coefficients for benzene were used for benzene oxide. The partition coefficients for phenol and hydroquinone were obtained by using an algorithm introduced by Poulin and Krishnan [30]. The method and the assumptions made in applying this algorithm are the same as in the SCL model. For more details of the algorithm, see Poulin and Krishnan [30, 31]. In addition to using the liver:blood partition coefficient as the richly perfused:blood partition coefficient for phenol and hydroquinone, the liver:blood partition coefficient was used as the kidney:blood partition coefficient for benzene, benzene oxide, phenol, and hydroquinone. The values of the partition coefficients used for benzene can be found in Table 1; those for phenol and hydroquinone are presented in Table 2.

\section{Existence and Uniqueness of Solutions}

For systems such as this one, we want to guarantee that we can find a solution and that the solution will be unique. Consider the autonomous system of nonlinear differential equations

$$
\dot{\vec{x}}=\vec{f}(\vec{x})
$$

with $\vec{x}\left(t_{0}\right)=\vec{x}_{0}$. Here,

$$
\vec{f}(\vec{x}): U \rightarrow \Re^{n},
$$

where $U$ is an open subset of $\Re^{n}, \vec{x}_{0} \in \Re^{n}$, and $t_{0} \in \Re$. We will examine whether $\vec{f}$ is locally Lipschitz, which is achieved by examining each component $f_{i}, i=1,2, \ldots, n$.

In this model for $i=1,2, \ldots n$, with $n=38$, each $f_{i}$ has the following form

$$
\begin{aligned}
f_{i}(\vec{x})=A_{i}+\sum_{j=1}^{n} B_{i_{j}} x_{j} H\left(x_{j}\right)+\sum_{k=1}^{n} D_{i_{k}} \frac{x_{k, 1} H\left(x_{k, 1}\right)}{K_{k}+x_{k, 1} H\left(x_{k, 1}\right)} \\
+\sum_{l=1}^{n} E_{i_{l}} \frac{x_{l, 1} H\left(x_{l, 1}\right)}{1+a_{l} x_{l, 1} H\left(x_{l, 1}\right)+b_{l} x_{l, 2} H\left(x_{l, 2}\right)+c_{l} x_{l, 3} H\left(x_{l, 3}\right)}
\end{aligned}
$$

where $A_{i}, B_{i_{j}}, D_{i_{j}}, E_{i_{j}}, K_{k}, a_{l}, b_{l}$, and $c_{l}$ are nonnegative constants, $x_{j}$ is the concentration in the $j t h$ tissue compartment and is the $j t h$ component of $\vec{x}, x_{p, q}$ is the qth component 
involved in the metabolism of the $p$ th tissue compartment where $q=j, k, l$ and $p=1,2,3$, and $H$ is the Heaviside function given by

$$
H\left(x_{j}\right)=\left\{\begin{array}{ll}
1 & x_{j} \geq 0 \\
0 & x_{j}<0
\end{array} .\right.
$$

We use the Heaviside function so as to guarantee that each component of $\vec{x}$ is nonnegative since the components represent amounts or concentrations and negative quantities would not be physically plausible. In our particular model the nonnegatively assumptions on $K_{k}, a_{j}$, $b_{k}$, and $c_{l}$ are true because $K_{k}$ is a concentration at half saturation and $a_{l}, b_{l}, c_{l}$ are affinities.

We will first show that each $f_{i}$ is locally Lipschitz, and thus $\vec{f}$ is locally Lipschitz. Let

$$
N_{\epsilon}\left(\vec{x}_{0}\right)=\left\{\vec{x} \in \Re^{n} \mid\left\|\vec{x}-\vec{x}_{0}\right\|<\epsilon\right\}
$$

where $\epsilon>0$ and the norm $\|\cdot\|$ is any equivalent norm in $\Re^{n}$. Let $\vec{\phi}$ and $\vec{\psi}$ be vectors in $N_{\epsilon}\left(\vec{x}_{0}\right)$. We begin by looking at the absolute value of the difference in $f_{i}$ evaluated at $\vec{\phi}$ and $\vec{\psi}$.

$$
\begin{aligned}
& \left|f_{i}(\vec{\phi})-f_{i}(\vec{\psi})\right|=\mid\left\{A_{i}+\sum_{j=1}^{n} B_{i_{j}} \phi_{j} H\left(\phi_{j}\right)+\sum_{k=1}^{n} D_{i_{k}} \frac{\phi_{k, 1} H\left(\phi_{k, 1}\right)}{K_{k}+\phi_{k, 1} H\left(\phi_{k, 1}\right)}\right. \\
& \left.+\sum_{l=1}^{n} E_{i_{j}} \frac{\phi_{l, 1} H\left(\phi_{l, 1}\right)}{1+a_{l} \phi_{l, 1} H\left(\phi_{l, 1}\right)+b_{l} \phi_{l, 2} H\left(\phi_{l, 2}\right)+c_{l} \phi_{l, 3} H\left(\phi_{l, 3}\right)}\right\} \\
& -\left\{A_{i}+\sum_{j=1}^{n} B_{i_{j}} \psi_{j} H\left(\psi_{j}\right)+\sum_{k=1}^{n} D_{i_{k}} \frac{\psi_{k, 1} H\left(\psi_{k, 1}\right)}{K_{k}+\psi_{k, 1} H\left(\psi_{k, 1}\right)}\right. \\
& \left.+\sum_{l=1}^{n} E_{i_{l}} \frac{\psi_{l, 1} H\left(\psi_{l, 1}\right)}{1+a_{l} \psi_{l, 1} H\left(\psi_{l, 1}\right)+b_{l} \psi_{l, 2} H\left(\psi_{l, 2}\right)+c_{l} \psi_{l, 3} H\left(\psi_{l, 3}\right)}\right\} \mid \\
& =\mid \sum_{j=1}^{n} B_{i_{j}} \phi_{j} H\left(\phi_{j}\right)+\sum_{k=1}^{n} D_{i_{k}} \frac{\phi_{k, 1} H\left(\phi_{k, 1}\right)}{K_{k}+\phi_{k, 1} H\left(\phi_{k, 1}\right)} \\
& +\sum_{l=1}^{n} E_{i_{l}} \frac{\phi_{l, 1} H\left(\phi_{l, 1}\right)}{1+a_{l} \phi_{l, 1} H\left(\phi_{l, 1}\right)+b_{l} \phi_{l, 2} H\left(\phi_{l, 2}\right)+c_{l} \phi_{l, 3} H\left(\phi_{l, 3}\right)} \\
& -\sum_{j=1}^{n} B_{i_{j}} \psi_{j} H\left(\psi_{j}\right)-\sum_{k=1}^{n} D_{i_{k}} \frac{\psi_{k, 1} H\left(\psi_{k, 1}\right)}{K_{k}+\psi_{k, 1} H\left(\psi_{k, 1}\right)} \\
& -\sum_{l=1}^{n} E_{i_{l}} \frac{\psi_{l, 1} H\left(\psi_{l, 1}\right)}{1+a_{l} \psi_{l, 1} H\left(\psi_{l, 1}\right)+b_{l} \psi_{l, 2} H\left(\psi_{l, 2}\right)+c_{l} \psi_{l, 3} H\left(\psi_{l, 3}\right)} \mid \\
& \leq \sum_{j=1}^{n}\left|B_{i_{j}}\left[\phi_{j} H\left(\phi_{j}\right)-\psi_{j} H\left(\psi_{j}\right)\right]\right| \\
& +\sum_{k=1}^{n}\left|D_{i_{k}}\left[\frac{\phi_{k, 1} H\left(\phi_{k, 1}\right)}{K_{k}+\phi_{k, 1} H\left(\phi_{k, 1}\right)}-\frac{\psi_{k, 1} H\left(\psi_{k, 1}\right)}{K_{k}+\psi_{k, 1} H\left(\psi_{k, 1}\right)}\right]\right| \\
& +\sum_{l=1}^{n} \mid E_{i_{l}}\left[\frac{\phi_{l, 1} H\left(\phi_{l, 1}\right)}{1+a_{l} \phi_{l, 1} H\left(\phi_{l, 1}\right)+b_{l} \phi_{l, 2} H\left(\phi_{l, 2}\right)+c_{l} \phi_{l, 3} H\left(\phi_{l, 3}\right)}\right. \\
& \left.-\frac{\psi_{l, 1} H\left(\psi_{l, 1}\right)}{1+a_{l} \psi_{l, 1} H\left(\psi_{l, 1}\right)+b_{l} \psi_{l, 2} H\left(\psi_{l, 2}\right)+c_{l} \psi_{l, 3} H\left(\psi_{l, 3}\right)}\right] \mid
\end{aligned}
$$




$$
\begin{aligned}
& \leq \sum_{j=1}^{n}\left|B_{i_{j}}\left[\phi_{j} H\left(\phi_{j}\right)-\psi_{j} H\left(\psi_{j}\right)\right]\right| \\
& +\sum_{k=1}^{n} D_{i_{k}} \mid\left\{\frac{K_{k} \phi_{k, 1} H\left(\phi_{k, 1}\right)+\phi_{k, 1} H\left(\phi_{k, 1}\right) \psi_{k, 1} H\left(\psi_{k, 1}\right)}{\left[K_{k}+\phi_{k, 1} H\left(\phi_{k, 1}\right)\right]\left[K_{k}+\psi_{k, 1} H\left(\psi_{k, 1}\right)\right]}\right. \\
& \left.-\frac{K_{k} \psi_{k, 1} H\left(\psi_{k, 1}\right)+\psi_{k, 1} H\left(\psi_{k, 1}\right) \phi_{k, 1} H\left(\phi_{k, 1}\right)}{\left[K_{k}+\phi_{k, 1} H\left(\phi_{k, 1}\right)\right]\left[K_{k}+\psi_{k, 1} H\left(\psi_{k, 1}\right)\right]}\right\} \mid \\
& +\sum_{l=1}^{n} E_{i_{l}}\left[\phi_{l, 1} H\left(\phi_{l, 1}\right)+\phi_{l, 1} H\left(\phi_{l, 1}\right) a_{l} \psi_{l, 1} H\left(\psi_{l, 1}\right)\right. \\
& +\phi_{l, 1} H\left(\phi_{l, 1}\right) b_{l} \psi_{l, 2} H\left(\psi_{l, 2}\right)+\phi_{l, 1} H\left(\phi_{l, 1}\right) c_{j} \psi_{l, 3} H\left(\psi_{l, 3}\right) \\
& -\psi_{l, 1} H\left(\psi_{l, 1}\right)-\psi_{l, 1} H\left(\psi_{l, 1}\right) a_{l} \phi_{l, 1} H\left(\phi_{l, 1}\right) \\
& \left.-\psi_{l, 1} H\left(\psi_{l, 1}\right) b_{l} \phi_{l, 2} H\left(\phi_{l, 2}\right)-\psi_{l, 1} H\left(\psi_{l, 1}\right) c_{l} \phi_{l, 3} H\left(\phi_{l, 3}\right)\right] \times \\
& \left\{\left[1+a_{l} \phi_{l, 1} H\left(\phi_{l, 1}\right)+b_{l} \phi_{l, 2} H\left(\phi_{l, 2}\right)+c_{l} \phi_{l, 3} H\left(\phi_{l, 3}\right)\right]\right. \\
& \left.\left[1+a_{l} \psi_{l, 1} H\left(\psi_{l, 1}\right)+b_{l} \psi_{l, 2} H\left(\psi_{l, 2}\right)+c_{l} \psi_{l, 3} H\left(\psi_{l, 3}\right)\right]\right\}^{-1} \\
& \leq \sum_{j=1}^{n}\left|B_{i_{j}}\left[\phi_{j} H\left(\phi_{j}\right)-\psi_{j} H\left(\psi_{j}\right)\right]\right| \\
& +\sum_{k=1}^{n} \mid D_{i_{k}}\left[\frac{K_{k} \phi_{k, 1} H\left(\phi_{k, 1}\right)+\phi_{k, 1} H\left(\phi_{k, 1}\right) \psi_{k, 1} H\left(\psi_{k, 1}\right)}{K_{k}^{2}}\right. \\
& \left.-\frac{K_{k} \psi_{k, 1} H\left(\psi_{k, 1}\right)+\psi_{k, 1} H\left(\psi_{k, 1}\right) \phi_{k, 1} H\left(\phi_{k, 1}\right)}{K_{k}^{2}}\right] \mid \\
& +\sum_{l=1}^{n} \mid E_{i_{l}}\left[\phi_{l, 1} H\left(\phi_{l, 1}\right)+\phi_{l, 1} H\left(\phi_{l, 1}\right) a_{l} \psi_{l, 1} H\left(\psi_{l, 1}\right)\right. \\
& +\phi_{l, 1} H\left(\phi_{l, 1}\right) b_{l} \psi_{l, 2} H\left(\psi_{l, 2}\right)+\phi_{l, 1} H\left(\phi_{l, 1}\right) c_{l} \psi_{l, 3} H\left(\psi_{l, 3}\right) \\
& -\psi_{l, 1} H\left(\psi_{l, 1}\right)-\psi_{l, 1} H\left(\psi_{l, 1}\right) a_{l} \phi_{l, 1} H\left(\phi_{l, 1}\right) \\
& \left.-\psi_{l, 1} H\left(\psi_{l, 1}\right) b_{l} \phi_{l, 2} H\left(\phi_{l, 2}\right)-\psi_{l, 1} H\left(\psi_{l, 1}\right) c_{l} \phi_{l, 3} H\left(\phi_{l, 3}\right)\right] \mid \\
& \leq \sum_{j=1}^{n}\left|B_{i_{j}}\left[\phi_{j} H\left(\phi_{j}\right)-\psi_{j} H\left(\psi_{j}\right)\right]\right| \\
& +\sum_{k=1}^{n}\left|D_{i_{k}}\left[\frac{K_{k} \phi_{k, 1} H\left(\phi_{k, 1}\right)-K_{k} \psi_{k, 1} H\left(\psi_{k, 1}\right)}{K_{k}^{2}}\right]\right| \\
& +\sum_{l=1}^{n} \mid E_{i_{l}}\left[\phi_{l, 1} H\left(\phi_{l, 1}\right)+\phi_{l, 1} H\left(\phi_{l, 1}\right) b_{l} \psi_{l, 2} H\left(\psi_{l, 2}\right)\right. \\
& +\phi_{l, 1} H\left(\phi_{l, 1}\right) c_{l} \psi_{l, 3} H\left(\psi_{l, 3}\right)-\psi_{l, 1} H\left(\psi_{l, 1}\right) \\
& \left.-\psi_{l, 1} H\left(\psi_{l, 1}\right) b_{l} \phi_{l, 2} H\left(\phi_{l, 2}\right)-\psi_{l, 1} H\left(\psi_{l, 1}\right) c_{l} \phi_{l, 3} H\left(\phi_{l, 3}\right)\right] \mid
\end{aligned}
$$




$$
\begin{aligned}
=\sum_{j=1}^{n} \mid & B_{i_{j}}\left[\phi_{j} H\left(\phi_{j}\right)-\psi_{j} H\left(\psi_{j}\right)\right] \mid \\
& +\sum_{k=1}^{n}\left|D_{i_{k}}\left[\frac{\phi_{k, 1} H\left(\phi_{k, 1}\right)-\psi_{k, 1} H\left(\psi_{k, 1}\right)}{K_{k}}\right]\right| \\
& +\sum_{l=1}^{n} \mid E_{i_{l}}\left\{\phi_{l, 1} H\left(\phi_{l, 1}\right)-\psi_{l, 1} H\left(\psi_{l, 1}\right)\right. \\
& +b_{l}\left[\phi_{l, 1} H\left(\phi_{l, 1}\right) \psi_{l, 2} H\left(\psi_{l, 2}\right)-\psi_{l, 1} H\left(\psi_{l, 1}\right) \phi_{l, 2} H\left(\phi_{l, 2}\right)\right] \\
& \left.+c_{l}\left[\phi_{l, 1} H\left(\phi_{l, 1}\right) \psi_{l, 3} H\left(\psi_{l, 3}\right)-\psi_{l, 1} H\left(\psi_{l, 1}\right) \phi_{l, 3} H\left(\phi_{l, 3}\right)\right]\right\} \mid \\
\leq \sum_{j=1}^{n} \mid & B_{i_{j}}|| \phi_{j} H\left(\phi_{j}\right)-\psi_{j} H\left(\psi_{j}\right) \mid \\
& +\sum_{k=1}^{n}\left|\frac{D_{i_{k}}}{K_{k}}\right|\left|\phi_{k, 1} H\left(\phi_{k, 1}\right)-\psi_{k, 1} H\left(\psi_{k, 1}\right)\right| \\
& +\sum_{l=1}^{n}\left[\left|E_{i_{l}}\right|\left|\phi_{l, 1} H\left(\phi_{l, 1}\right)-\psi_{l, 1} H\left(\psi_{l, 1}\right)\right|\right. \\
& +\left|E_{i_{l}} b_{l}\right|\left|\phi_{l, 1} H\left(\phi_{l, 1}\right) \psi_{l, 2} H\left(\psi_{l, 2}\right)-\psi_{l, 1} H\left(\psi_{l, 1}\right) \phi_{l, 2} H\left(\phi_{l, 2}\right)\right| \\
& +\left|E_{i_{l}} c_{l}\right| \mid \phi_{l, 1} H\left(\phi_{l, 1}\right) \psi_{l, 3} H\left(\psi_{l, 3}\right) \\
& \left.-\psi_{l, 1} H\left(\psi_{l, 1}\right) \phi_{l, 3} H\left(\phi_{l, 3}\right) \mid\right]
\end{aligned}
$$

We now examine various cases:

1. If $\phi_{j}, \psi_{j} \geq 0$, then

$$
\begin{aligned}
\left|\phi_{j} H\left(\phi_{j}\right)-\psi_{j} H\left(\psi_{j}\right)\right| & =\left|\phi_{j}-\psi_{j}\right| \\
& \leq\|\phi-\psi\| .
\end{aligned}
$$

2. If $\phi_{j}, \psi_{j}<0$, then

$$
\begin{aligned}
\left|\phi_{j} H\left(\phi_{j}\right)-\psi_{j} H\left(\psi_{j}\right)\right| & =0 \\
& \leq\|\phi-\psi\| .
\end{aligned}
$$

3. If $\phi_{j} \geq 0$ and $\psi_{j}<0$, then we use this information coupled with the definition of absolute value to obtain the following:

$$
\begin{aligned}
\left|\phi_{j} H\left(\phi_{j}\right)-\psi_{j} H\left(\psi_{j}\right)\right| & =\left|\phi_{j}\right| \\
& <|| \phi_{j}|+| \psi_{j}|| \\
& =\left|\phi_{j}-\psi_{j}\right| \\
& \leq\|\phi-\psi\| .
\end{aligned}
$$

The same is true if $\phi_{j}<0$ and $\psi_{j} \geq 0$. 
Thus, for any $\phi_{j}$ and any $\psi_{j}$,

$$
\left|\phi_{j} H\left(\phi_{j}\right)-\psi_{j} H\left(\psi_{j}\right)\right| \leq\|\phi-\psi\| .
$$

We note that these same argument could be used with $\phi_{k, 1}$ and $\psi_{k, 1}$ to obtain the local Lipschitz condition:

$$
\left|\phi_{k, 1} H\left(\phi_{k, 1}\right)-\psi_{k, 1} H\left(\psi_{k, 1}\right)\right| \leq\|\phi-\psi\| \text {. }
$$

Let us now look at several of the other terms in equation (1). By the previous argument, we know that

$$
\left|\phi_{l, 1} H\left(\phi_{l, 1}\right)-\psi_{l, 1} H\left(\psi_{l, 1}\right)\right| \leq\|\phi-\psi\| \text {. }
$$

For the expression

$$
\left|\phi_{l, 1} H\left(\phi_{l, 1}\right) \psi_{l, 2} H\left(\psi_{l, 2}\right)-\psi_{l, 1} H\left(\psi_{l, 1}\right) \phi_{l, 2} H\left(\phi_{l, 2}\right)\right|,
$$

we again examine several cases. We note that these arguments apply to the term

$$
\left|\phi_{l, 1} H\left(\phi_{l, 1}\right) \psi_{l, 3} H\left(\psi_{l, 3}\right)-\psi_{l, 1} H\left(\psi_{l, 1}\right) \phi_{l, 3} H\left(\phi_{l, 3}\right)\right|
$$

as well.

1. If $\phi_{l, 1}, \phi_{l, 2}, \psi_{l, 1}, \psi_{l, 2} \geq 0$,

$$
\begin{aligned}
\mid \phi_{l, 1} H\left(\phi_{l, 1}\right) \psi_{l, 2} H\left(\psi_{l, 2}\right) & -\psi_{l, 1} H\left(\psi_{l, 1}\right) \phi_{l, 2} H\left(\phi_{l, 2}\right) \mid \\
= & \left|\phi_{l, 1} \psi_{l, 2}-\psi_{l, 1} \phi_{l, 2}\right| \\
= & \left|\phi_{l, 1} \psi_{l, 2}-\psi_{l, 1} \phi_{l, 2}+\phi_{l, 1} \phi_{l, 2}-\phi_{l, 1} \phi_{l, 2}\right| \\
& =\left|\phi_{l, 1}\left(\psi_{l, 2}-\phi_{l, 2}\right)+\phi_{l, 2}\left(\phi_{l, 1}-\psi_{l, 1}\right)\right| \\
& \leq\left|\phi_{l, 1}\right|\left|\psi_{l, 2}-\phi_{l, 2}\right|+\left|\phi_{l, 2}\right|\left|\phi_{l, 1}-\psi_{l, 1}\right| \\
& \leq\left(\left|\phi_{l, 1}\right|+\left|\phi_{l, 2}\right|\right)\|\phi-\psi\| .
\end{aligned}
$$

Thus, since $\phi_{l, 1}$ and $\phi_{l, 2}$ are finite components of $\vec{\phi}$, we know these components are bounded.

2. If any of the following pairs are negative:

- $\phi_{l, 1}, \psi_{l, 1}<0$

- $\phi_{l, 1}, \phi_{l, 2}<0$

- $\phi_{l, 2}, \psi_{l, 2}<0$

- $\psi_{l, 1}, \psi_{l, 2}<0$ 
then

$$
\begin{aligned}
\left|\phi_{l, 1} H\left(\phi_{l, 1}\right) \psi_{l, 2} H\left(\psi_{l, 2}\right)-\psi_{l, 1} H\left(\psi_{l, 1}\right) \phi_{l, 2} H\left(\phi_{l, 2}\right)\right| & =0 \\
& \leq\|\phi-\psi\| .
\end{aligned}
$$

3. If $\phi_{l, 1}, \psi_{l, 2} \geq 0$ and $\psi_{l, 1}<0$, then

$$
\begin{aligned}
\left|\phi_{l, 1} H\left(\phi_{l, 1}\right) \psi_{l, 2} H\left(\psi_{l, 2}\right)-\psi_{l, 1} H\left(\psi_{l, 1}\right) \phi_{l, 2} H\left(\phi_{l, 2}\right)\right| & =\left|\phi_{l, 1} \psi_{l, 2}\right| \\
& \leq|| \phi_{l, 1} \psi_{l, 2}|+| \psi_{l, 1} \psi_{l, 2}|| \\
& =\left|\phi_{l, 1} \psi_{l, 2}-\psi_{l, 1} \psi_{l, 2}\right| \\
& \leq\left|\psi_{l, 2}\right|\left|\phi_{l, 1}-\psi_{l, 1}\right| \\
& \leq\left|\psi_{l, 2}\right| \mid \phi_{-} \psi \| .
\end{aligned}
$$

Since $\psi_{l, 2}$ is bounded, this term is locally Lipschitz. This argument also holds for the following combinations:

- $\phi_{l, 1}, \psi_{l, 2} \geq 0$ and $\phi_{l, 2}<0$

- $\phi_{l, 2}, \psi_{l, 1} \geq 0$ and $\phi_{l, 1}<0$

- $\phi_{l, 2}, \psi_{l, 1} \geq 0$ and $\psi_{l, 2}<0$

Thus, we have shown that each term in equation (1) is locally Lipschitz; therefore, the $f_{i}$ are locally Lipschitz.

Therefore, the existence and uniqueness of a solution to our system $\dot{\vec{x}}=\vec{f}(\vec{x})$ with $\vec{x}\left(t_{0}\right)=\vec{x}_{0}$ is guaranteed by the following theorem.

Theorem 1: Existence and Uniqueness of Solutions of Ordinary Differential Equations. Let $U \subset \Re^{n}$ be an open set, and let $\vec{f}: U \rightarrow \Re^{n}$ be a (local) Lipschitz function. Let $\vec{x}_{0} \in U$ and $t_{0} \in \Re$. There there exists an $\alpha>0$ and a solution, $\vec{x}(t)$, of $\dot{\vec{x}}=\vec{f}(\vec{x})$ defined for $t_{0}-\alpha<t<t_{0}+\alpha$ such that $\vec{x}\left(t_{0}\right)=\vec{x}_{0}$. Moreover, if $\vec{y}(t)$ is another solution with $\vec{y}\left(t_{0}\right)=\vec{x}_{0}$, then $\vec{x}(t)=\vec{y}(t)$ on their common interval of definition about $t_{0}$. [32]

\section{The Inverse Problem}

In order for models to be useful, we must have values for all parameters in the model; often, some of these are unknown. Through the optimization of a cost function, we can find values for these parameters by varying the parameters to fit the solutions found from simulations to the experimental data.

Although we can find a set of parameters that is an optimal set, we emphasize that this is not an unique set of parameters. This problem of parameter identifiability has been discussed extensively by Banks and Kunisch [4]; we direct the reader there for more details.

Optimizations were performed using a combination of Nelder-Mead and Hooke-Jeeves methods. Both of these algorithms are simplex methods. Nelder-Mead maintains a simplex $S$ relative to an optimal point; this simplex is updated after each iteration. Hooke-Jeeves is 
evaluated on a stencil and computes function values which are used to find possible search directions. For a further description of these methods, we refer the interested reader to Iterative Methods of Optimization [10]. All of our computations are done in MATLAB (The Math Works, Inc., Natick, Massachusetts).

The model consists of 38 nonlinear ordinary differential equations, which are listed in Appendix B. These equations incorporate the various rates of metabolism discussed previously.

For our PBPK model, there are five unknown parameters: $k_{3}$, the rate constant for the metabolism of benzene oxide to muconic acid; $k_{4}$, the rate constant for the metabolism of benzene oxide to phenylmercapturic acid; $k_{8}$, the rate constant for the uptake from the stomach to the liver; $k_{9}$, the binding constant for phenol to tissue; and $k_{10}$, the binding constant for hydroquinone to tissue. These five parameters were estimated, just as they were for the SCL model. But, unlike with the SCL model, we used the previously published values for $C^{C P}$ and $C^{M P}$. Instead, we estimated the maximum rates of metabolism $V_{2 E 1}, V_{P H, 1}$, $V_{P H, 2}$, and $V_{H Q}$, although these rates had been reported previously. The hepatic metabolism is disrupted when microsomal samples are used; thus the maximum rates of metabolisms may not have been measured accurately. The previously measured rates given by Seaton et al. [35] were $0.0221 \mu \mathrm{mol} / \mathrm{mg}$ protein $/ \mathrm{hr}, 0.295 \mu \mathrm{mol} / \mathrm{mg}$ protein $/ \mathrm{hr}$, and $1.0456 \mu \mathrm{mol} / \mathrm{mg}$ protein/hr for $V_{P H 1}, V_{P H 2}$, and $V_{H Q}$, repsectively. The result of $141 \mathrm{nmol} / \mathrm{mg} / \mathrm{hr}$ for $V_{2 E 1}$ was an unpublished result.

To estimate these parameters, we used a modified maximum likelihood estimator similar to the one used by the program SIMUSOLV [36]. A derivation of the modified maximum likelihood function can be found in Cole et al. [6]. The modified maximum likelihood function is given by

$$
J(\theta)=-\frac{1}{2} \sum_{i=1}^{r}\left\{n_{i}[\log (2 \pi)+1]+\gamma_{i} \sum_{j=1}^{n_{i}} \log f_{i, j}+n_{i} \log \left(\frac{1}{n_{i}} \sum_{j=1}^{n_{i}} \frac{\left(z_{i, j}-f_{i, j}\right)^{2}}{f_{i, j}^{\gamma_{i}}}\right)\right\}
$$

where

- $J$ is the cost given $\theta$.

- $\theta$ is the set of parameter values.

- $r$ is the number of response (dependent) variables.

- $n_{i}$ is the number of measurements of the $i$ th response.

- $n$ is the total number of measurements, i.e., $n=\sum_{i=1}^{r} n_{i}$.

- $z_{i, j}$ is the observed value of the $i$ th response at the $j$ th data point.

- $f_{i, j}$ is the predicted value of the $i$ th response at the $j$ th data point.

For each variable for which we have data, there is a heteroscedasticity parameter, $\gamma_{j}$; each $\gamma_{j}$ is bound between 0 and 2. The closer $\gamma_{j}$ is to 0 , the closer the objective function is to being an absolute error; when $\gamma_{j}$ is close to 2 , the closer the objective function is to measuring a relative error. The $\gamma_{j}, j=1, \ldots, 10$ in this study, were estimated as well as 
the unknown model parameters described above. Since simplex methods can stagnate, the optimizations were restarted multiple times until no improvement in the cost function was obtained.

\section{Results}

The heteroscedasticity, $\gamma_{j}$, associated with the amount of phenylmercapturic acid, phenol conjugates, hydroquinone conjugates, and benzene exhaled as well as the concentration of phenol in the liver were all 2. The $\gamma_{j}$ was 1.83 for the amount of muconic acid and 0.23 for the concentration of benzene in the liver. For phenol in the blood, $\gamma_{j}$ was 1.52. For the phenol and hydroquinone in the liver, the $\gamma_{j}$ were 1.25 and 1.09 respectively. Thus, the objective function was closer to a relative error than an absolute error for most parameters since many of the $\gamma_{j}$ were close to or equal to 2 .

Optimal metabolic parameters that were obtained are given in Table 3.

Using the optimal parameters, this PBPK model, denoted as the MCL model in the tables and figures, predicted the data reasonably well (see Figures 3 and 4 and Tables 4 and 5) and improved the fit over the SCL model. As in the SCL model, the muconic acid and phenylmercapturic acid data were very accurately predicted. The model gave qualitatively accurate predictions of the time course data for the amount of benzene exhaled (see Figure 3). The predictions of the amount of benzene exhaled improved, giving very accurate estimates when considering multiple dose levels (see Figure 4). Additionally, we see much improvement in the fit of the tissue concentration data; we believe that extrahepatic metabolism as well as the zonal distribution of metabolism in the liver is significant and thus incorporating these into the model accounts for much of the improvement. The predictions for the phenol and hydroquinone conjugates still exhibit the behavior that the smallest and largest dose levels, which come from the studies of Mathews et al. [22], are overpredicted while the intermediate dose levels, taken from the work of Kenyon et al. [11], are underpredicted. The overpredictions and underpredictions do not have a linear correspondence to the dose levels but rather are laboratory dependent.

\section{Discussion}

The PBPK model described here takes into account various forms of benzene metabolism, including those mediated by CYP2E1, as well as uptake after both oral and inhalation exposure. Multiple tissue compartments were used for the key metabolites of benzene, while single urinary compartments were used for the metabolites and conjugates of benzene oxide, phenol, and hydroquinone. Nonenzymatic metabolism in all tissues and CYP2E1-mediated metabolism in the kidney as well as the zonal distribution of enzymes in the liver were included.

There are also several sources of variability in the data. First, the data sets that were from multiple, independent laboratories, so the analytic techniques varied. Second, for each of these simulations we used published average body weights, blood flows, and organ volumes since the specific measurements for the mice in the individual experiments were unavailable. Third, these data sets represented both inhalation and gavage administration of benzene. 
Given these unavoidable variations, the model did a sufficient job predicting the tissue doses as well as the amount of metabolites in the urine and exhaled air. It would also be helpful if there were more data available in which oral administration experiments measured tissue concentrations or inhalation exposure experiments measured urinary metabolites.

In the future, we hope to use the parameters that were obtained and extrapolate the model from rodents to humans for use in risk assessment. We also hope to use the tissue concentration levels as input to a model for benzene's effects on hematopoiesis. We are currently implementing a model for erythropoiesis to this end. It is known that erythrocytes are the most sensitive of the cellular elements to benzene toxicity in the blood. A modified age-structured model for the regulation of erythropoiesis that includes a death rate term for cell losses due benzene exposure is being developed. Since leukemia is a major concern following benzene exposure, the erythropoiesis model, in conjunction with the PBPK model described here, could allow us to predict what levels of exposure would invoke potential hazard to the blood cell production.

\section{Acknowledgments}

Cammey E. Cole was supported via a fellowship from CIIT Centers for Health Research while she was a graduate student in the Center for Research in Scientific Computation at North Carolina State University.

\section{Appendices}

\subsection{Appendix A: Symbols}

The following symbols and abbreviations are used throughout the article. Units of the symbols are given in parentheses.

\subsubsection{Chemical Abbreviations}

$\begin{array}{ll}B Z & \text { Benzene } \\ B O & \text { Benzene Oxide } \\ P H & \text { Phenol } \\ H Q & \text { Hydroquinone } \\ M A & \text { Muconic Acid } \\ P M A & \text { Phenylmercapturic Acid } \\ \text { PH }- \text { Conj } & \text { Phenol Conjugates } \\ H Q-\text { Conj } & \text { Hydroquinone Conjugates } \\ \text { Cat } & \text { Catechol } \\ \text { THB } & \text { Trihydroxy benzene }\end{array}$

\subsubsection{Compartment Abbreviations}

F $\quad$ Fat

$S \quad$ Slowly or Poorly Perfused Tissue 
$R \quad$ Rapidly or Richly Perfused Tissue

$K \quad$ Kidney

L1 Zone 1 of the Liver

L2 Zone 2 of the Liver

L3 Zone 3 of the Liver

$\mathrm{Bl} \quad$ Blood

Stom Stomach

I Inhaled air

E Exhaled air

\subsubsection{Primary Symbols}

$C_{j}^{i} \quad$ Concentration of chemical $i$ in tissue $j(\mu \mathrm{mol} / \mathrm{L})$

$C A^{B Z} \quad$ Concentration of BZ in the arterial blood $(\mu \mathrm{mol} / \mathrm{L})$

$C V^{B Z} \quad$ Concentration of $\mathrm{BZ}$ in venous blood $(\mu \mathrm{mol} / \mathrm{L})$

$C V_{j}^{i} \quad$ Concentration of chemical $i$ in venous blood from

tissue $j(\mu \mathrm{mol} / \mathrm{L})$

$C_{I}^{B Z} \quad$ Concentration of BZ in inhaled air $(\mu \mathrm{mol} / \mathrm{L})$

$C_{E}^{B Z} \quad$ Concentration of BZ in exhaled air $(\mu \mathrm{mol} / \mathrm{L})$

$A M^{i} \quad$ Amount of chemical $i$ in urine $(\mu \mathrm{mol})$

$A M^{\text {Stom }} \quad$ Amount of BZ in the stomach $(\mu \mathrm{mol})$

$R M_{j}^{i} \quad$ Rate of metabolism of chemical $i$ to chemical $j(\mu \mathrm{mol} / \mathrm{hr})$

$Q_{j} \quad$ Flow in tissue $j(\mathrm{~L} / \mathrm{hr})$

$Q_{A v V} \quad$ Alveolar ventilation $(\mathrm{L} / \mathrm{hr})$

$Q_{\text {Card }} \quad$ Cardiac blood output (L/hr)

$P_{j}^{i}$

$P_{B l: A i r}^{B Z}$ Tissue $j$ /blood partition coefficient for chemical $i$

$B W$

Blood/air partition coefficient for BZ

$V_{j} \quad$ Volume of tissue $j(\mathrm{~L})$

$T_{L} \quad$ Total mass of the liver $(\mathrm{g})$

$C^{M P} \quad$ Concentration of microsomal protein per gram of tissue in the liver $(\mathrm{mg} / \mathrm{g})$

$C^{C P} \quad$ Concentration of cytosolic protein per gram of tissue in the liver $(\mathrm{mg} / \mathrm{g})$

$V_{2 E 1} \quad$ CYP2E1 specific activity as determined by the oxidation of p-nitrophenol to p-nitrocatechol (nmol/mg/hr)

$A^{i} \quad$ Affinity parameter for CYP2E1 for substrate $i(\mathrm{~L} / \mu \mathrm{mol})$

$k_{1}, k_{5}-k_{7} \quad$ Efficiencies of CYP2E1 for specific oxidations relative to $V_{2 E 1}(\mathrm{~L} / \mathrm{nmol})$

$k_{2}-k_{4} \quad$ First-order rates of metabolism $(1 / \mathrm{hr})$

$k_{8} \quad$ Rate of uptake from the stomach to the liver $(1 / \mathrm{hr})$

$k_{9}, k_{10} \quad$ Binding coefficients $(1 / \mathrm{hr})$

$V_{P H 1}, V_{P H 2}$ Maximum rates of metabolism of $\mathrm{PH}$ by two sulfate transferases $(\mu \mathrm{mol} / \mathrm{mg} / \mathrm{hr})$

$K_{m, 1}^{P H}, K_{m, 2}^{P H}$ Concentrations at half-saturation of $\mathrm{PH}$ by two 
sulfate transferases $(\mu \mathrm{mol} / \mathrm{L})$

$V_{H Q} \quad$ Maximum rate of metabolism for $\mathrm{HQ}(\mu \mathrm{mol} / \mathrm{mg} / \mathrm{hr})$

$K_{m}^{H Q} \quad$ Concentration at half-saturation for $\mathrm{HQ}(\mu \mathrm{mol} / \mathrm{L})$

\subsection{Appendix B: Differential Equations}

The following differential equations were derived using basic mass balance principles and incorporate the metabolism rate equations discussed previously. Equations are grouped by chemical.

$\underline{\text { Benzene }}$

$$
\begin{aligned}
\text { Fat: } V_{F} \frac{d C_{F}^{B Z}}{d t} & =Q_{F}\left(C A^{B Z}-C V_{F}^{B Z}\right) \\
\text { Slowly: } V_{S} \frac{d C_{S}^{B Z}}{d t} & =Q_{S}\left(C A^{B Z}-C V_{S}^{B Z}\right) \\
\text { Rapidly: } V_{R} \frac{d C_{R}^{B Z}}{d t} & =Q_{R}\left(C A^{B Z}-C V_{R}^{B Z}\right) \\
\text { Kidney: } V_{K} \frac{d C_{K}^{B Z}}{d t} & =Q_{K}\left(C A^{B Z}-C V_{K}^{B Z}\right)-R M_{B O, K}^{B Z} \\
\text { Liver (Zone 1): } \frac{V_{L}}{3} \frac{d C_{L 1}^{B Z}}{d t} & =Q_{L}\left(C A^{B Z}-C_{L 1}^{B Z}\right)+k_{8} A M^{S t o m} \\
\text { Liver (Zone 2): } \frac{V_{L}}{3} \frac{d C_{L 2}^{B Z}}{d t} & =Q_{L}\left(C_{L 1}^{B Z}-C_{L 2}^{B Z}\right) \\
\text { Liver (Zone 3): } \frac{V_{L}}{3} \frac{d C_{L 3}^{B Z}}{d t} & =Q_{L}\left(C_{L 2}^{B Z}-C V_{L 3}^{B Z}\right)-R M_{B O, L 3}^{B Z} \\
\text { Stomach: } \frac{d A M^{S t o m}}{d t} & =-k_{8} A M^{S t o m} \\
\text { Exhaled: } \frac{d A M_{E}^{B Z}}{d t} & =Q_{C a r d}\left(C V^{B Z}-C A^{B Z}\right)+Q_{A v V} * C_{I}^{B Z}
\end{aligned}
$$

Benzene Oxide

$$
\begin{aligned}
& \text { Blood: } V_{B l} \frac{d C_{B l}^{B O}}{d t}=Q_{F} C V_{F}^{B O}+Q_{S} C V_{S}^{B O}+Q_{R} C V_{R}^{B O} \\
& +Q_{K} C V_{K}^{B O}+Q_{L} C V_{L 3}^{B O}-Q_{C a r d} C_{B l}^{B O} \\
& -R M_{P M A, B l}^{B O}-R M_{P H, B l}^{B O} \\
& \text { Fat: } V_{F} \frac{d C_{F}^{B O}}{d t}=Q_{F}\left(C_{B l}^{B O}-C V_{F}^{B 0}\right)-R M_{P M A, F}^{B O}-R M_{P H, F}^{B O} \\
& \text { Slowly: } V_{S} \frac{d C_{S}^{B O}}{d t}=Q_{S}\left(C_{B l}^{B O}-C V_{S}^{B O}\right)-R M_{P M A, S}^{B O}-R M_{P H, S}^{B O} \\
& \text { Rapidly: } V_{R} \frac{d C_{R}^{B O}}{d t}=Q_{R}\left(C_{B l}^{B O}-C V_{R}^{B O}\right)-R M_{P M A, R}^{B O}-R M_{P H, R}^{B O} \\
& \text { Kidney: } V_{K} \frac{d C_{K}^{B O}}{d t}=Q_{K}\left(C_{B l}^{B O}-C V_{K}^{B O}\right)+R M_{B O, K}^{B Z}
\end{aligned}
$$




$$
-R M_{P H, K}^{B O}-R M_{P M A, K}^{B O}
$$

Liver (Zone 1): $\frac{V_{L}}{3} \frac{d C_{L 1}^{B O}}{d t}=Q_{L}\left(C_{B l}^{B O}-C_{L 1}^{B O}\right)-R M_{P H, L 1}^{B O}$

Liver (Zone 2): $\frac{V_{L}}{3} \frac{d C_{L 2}^{B O}}{d t}=Q_{L}\left(C_{L 1}^{B O}-C_{L 2}^{B O}\right)-R M_{P H, L 2}^{B O}$

Liver (Zone 3): $\frac{V_{L}}{3} \frac{d C_{L 3}^{B O}}{d t}=Q_{L}\left(C_{L 2}^{B O}-C V_{L 3}^{B O}\right)+R M_{B O, L 3}^{B Z}$

$$
-R M_{P H, L 3}^{B O}-R M_{M A, L 3}^{B O}-R M_{P M A, L 3}^{B O}
$$

Muconic Acid

$$
\frac{d A M^{M A}}{d t}=R M_{M A, L 3}^{B O}
$$

Phenylmercapturic Acid

$$
\begin{aligned}
\frac{d A M^{P M A}}{d t}= & R M_{P M A, B l}^{B O}+R M_{P M A, F}^{B O}+R M_{P M A, S}^{B O} \\
& +R M_{P M A, R}^{B O}+R M_{P M A, K}^{B O}+R M_{P M A, L 3}^{B O}
\end{aligned}
$$

Phenol

$$
\begin{aligned}
& \text { Blood: } V_{B l} \frac{d C_{B l}^{P H}}{d t}=Q_{F} C V_{F}^{P H}+Q_{S} C V_{S}^{P H}+Q_{R} C V_{R}^{P H} \\
& \begin{array}{l}
+Q_{K} C V_{K}^{P H}+Q_{L} C V_{L 3}^{P H}-Q_{C a r d} C_{B l}^{P H} \\
+R M_{P H, B l}^{B O}-k_{9} C_{B l}^{P H} V_{B l}
\end{array} \\
& \text { Fat: } V_{F} \frac{d C_{F}^{P H}}{d t}=Q_{F}\left(C_{B l}^{P H}-C V_{F}^{P H}\right)+R M_{P H, F}^{B O}-k_{9} C_{F}^{P H} V_{F}
\end{aligned}
$$

Slowly: $V_{S} \frac{d C_{S}^{P H}}{d t}=Q_{S}\left(C_{B l}^{P H}-C V_{S}^{P H}\right)+R M_{P H, S}^{B O}-k_{9} C_{S}^{P H} V_{S}$

Rapidly: $V_{R} \frac{d C_{R}^{P H}}{d t}=Q_{R}\left(C_{B l}^{P H}-C V_{R}^{P H}\right)+R M_{P H, R}^{B O}-k_{9} C_{R}^{P H} V_{R}$

Kidney: $V_{K} \frac{d C_{K}^{P H}}{d t}=Q_{K}\left(C_{B l}^{P H}-C V_{K}^{P H}\right)+R M_{P H, K}^{B O}$

$$
-R M_{H Q, K}^{P H}-R M_{C a t, K}^{P H}-k_{9} C_{K}^{P H} V_{K}
$$

Liver (Zone 1): $\frac{V_{L}}{3} \frac{d C_{L 1}^{P H}}{d t}=Q_{L}\left(C_{B l}^{P H}-C_{L 1}^{P H}\right)+R M_{P H, L 1}^{B O}$

$$
-R M_{C o n j, L 1}^{P H}-k_{9} C_{L 1}^{P H} \frac{V_{L}}{3}
$$

Liver (Zone 2): $\frac{V_{L}}{3} \frac{d C_{L 2}^{P H}}{d t}=Q_{L}\left(C_{L 1}^{P H}-C_{L 2}^{P H}\right)+R M_{P H, L 2}^{B O}-k_{9} C_{L 2}^{P H} \frac{V_{L}}{3}$

Liver (Zone 3): $\frac{V_{L}}{3} \frac{d C_{L 3}^{P H}}{d t}=Q_{L}\left(C_{L 2}^{P H}-C V_{L 3}^{P H}\right)+R M_{P H, L 3}^{B O}$

$$
-R M_{H Q, L 3}^{P H}-R M_{C a t, L 3}^{P H}-k_{9} C_{L 3}^{P H} \frac{V_{L}}{3}
$$


$\underline{\text { Phenol Conjugates }}$

$$
\frac{d A M^{P H-C o n j}}{d t}=R M_{C o n j, L 1}^{P H}
$$

$\underline{\text { Hydroquinone }}$

$$
\begin{aligned}
& \text { Blood: } V_{B l} \frac{d C_{B l}^{H Q}}{d t}=Q_{F} C V_{F}^{H Q}+Q_{S} C V_{S}^{H Q}+Q_{R} C V_{R}^{H Q} \\
& +Q_{K} C V_{K}^{H Q}+Q_{L} C V_{L}^{H Q} \\
& -Q_{C a r d} C_{B l}^{H Q}-k_{10} C_{B l}^{H Q} V_{B l} \\
& \text { Fat: } V_{F} \frac{d C_{F}^{H Q}}{d t}=Q_{F}\left(C_{B l}^{H Q}-C V_{F}^{H Q}\right)-k_{10} C_{F}^{H Q} V_{F} \\
& \text { Slowly: } V_{S} \frac{d C_{S}^{H Q}}{d t}=Q_{S}\left(C_{B l}^{H Q}-C V_{S}^{H Q}\right)-k_{10} C_{S}^{H Q} V_{S} \\
& \text { Rapidly: } V_{R} \frac{d C_{R}^{H Q}}{d t}=Q_{R}\left(C_{B l}^{H Q}-C V_{R}^{H Q}\right)-k_{10} C_{R}^{H Q} V_{R} \\
& \text { Kidney: } V_{K} \frac{d C_{K}^{H Q}}{d t}=Q_{K}\left(C_{B l}^{H Q}-C V_{K}^{H Q}\right)+R M_{H Q, K}^{P H} \\
& -R M_{T H B, K}^{H Q}-k_{10} C_{K}^{H Q} V_{K} \\
& \text { Liver (Zone 1): } \frac{V_{L}}{3} \frac{d C_{L 1}^{H Q}}{d t}=Q_{L}\left(C_{B l}^{H Q}-C_{L 1}^{H Q}\right)-k_{10} C_{L 1}^{H Q} \frac{V_{L}}{3} \\
& \text { Liver (Zone 2): } \frac{V_{L}}{3} \frac{d C_{L 2}^{H Q}}{d t}=Q_{L}\left(C_{L 1}^{H Q}-C_{L 2}^{H Q}\right)-k_{10} C_{L 2}^{H Q} \frac{V_{L}}{3} \\
& \text { Liver (Zone 3): } \frac{V_{L}}{3} \frac{d C_{L 3}^{H Q}}{d t}=Q_{L}\left(C_{L 2}^{H Q}-C V_{L 3}^{H Q}\right)+R M_{H Q, L 3}^{P H} \\
& -R M_{T H B, L 3}^{H Q}-R M_{C o n j, L 3}^{H Q}-k_{10} C_{L 3}^{H Q} \frac{V_{L}}{3}
\end{aligned}
$$

$\underline{\text { Hydroquinone Conjugates }}$

$$
\frac{d A M^{H Q-C o n j}}{d t}=R M_{C o n j, L 3}^{H Q}
$$

Catechol and Trihydroxy benzene

$$
\frac{d A M^{C a t / T H B}}{d t}=R M_{C a t, L 3}^{P H}+R M_{C a t, K}^{P H}+R M_{T H B, L 3}^{H Q}+R M_{T H B, K}^{H Q}
$$

\section{References}

[1] Melvin E. Andersen, Christopher R. Eklund, Jeremy J. Mills, Hugh A. Barton, and Linda S. Birnbaum. A multicompartment geometric model of the liver in relation to regional induction of cytochrome P450s. Toxicol. Appl. Pharmacol., 144:135-144, 1997. 
[2] Larry S. Andrews, H.A. Sasame, and James R. Gilletter. ${ }^{3}$ h-Benzene metabolism in rabbit bone marrow. Life Sci., 25:567-572, 1979.

[3] Angela D. Arms and Curtis C. Travis. Reference physiological parameters in pharmacokinetic modeling. Technical report, Office of Risk Analysis, Oak Ridge National Laboratory, February 1998.

[4] H.T. Banks and K. Kunisch. Estimation Techniques for Distributed Parameter Systems. Birkhäuser, 1989.

[5] Ann M. Chaney and Gary P. Carlson. Comparison of rat hepatic and pulmonary microsomal metabolism of benzene and the lack of benzene-induced pneumotoxicity and hepatotoxicity. Toxicology, 104:53-62, 1995.

[6] Cammey E. Cole, Hien T. Tran, and Paul M. Schlosser. Physiologically based pharmacokinetic modeling of benzene metabolism in mice through extrapolation from in vitro to in vivo. J. Toxicol. Environ. Health, 62:439-465, 2001.

[7] I. de Waziers, P.H. Cugnenc, C.S. Lang, J.-P. Leroux, and P.H. Beaune. Cytochrome P 450 isoenzymes, epoxide hydrolase and glutathione transferases in rat and human hepatic and extrahepatic tissues. J. Pharmacol. Exp. Ther., 253:387-394, 1990.

[8] Matthew J. Hoffman, Sungchul Ji, Christine C. Hedli, and Robert Snyder. Metabolism of $\left[{ }^{14} \mathrm{C}\right]$ phenol in the isolated perfused mouse liver. Toxicol. Sci., 49:40-47, 1999.

[9] George Kalf. Recent advances in the metabolism and toxicity of benzene. CRC Crit. Rev. Toxicol., 18:141-159, 1987.

[10] C.T. Kelley. Iterative Methods for Optimization. SIAM, 1999.

[11] Elaina M. Kenyon, Maureen E. Seeley, Derek Janszen, and Michele A. Medinsky. Dose-, route-, and sex-dependent urinary excretion of phenol metabolites of $\mathrm{B}_{6} \mathrm{C} 3 \mathrm{~F}_{1}$ mice. J. Toxicol. Environ. Health, 44:219-233, 1995.

[12] Wouter H. Lamers, Aage Hilberts, Erwin Furt, Jerry Smith, Geertruida N. Jonges, Cornelis J. F. van Noorden, Jan Willem Gaasbeek Janzen, Robert Charles, and Antoon Moorman. Hepatic enzymic zonation: A reevaluation of the concept of the liver acinus. Hepatology, 10(1):72-76, 1989.

[13] Chi-Yu Gregory Lee. Multiple forms of mouse glutathione s-transferase. Biochem. Soc. Trans., 12:30-33, February 1984.

[14] Agnes Legathe, Betty-Ann Hoener, and Thomas N. Tozer. Pharmacokinetic interaction between benzene metabolites, phenol and hydroquinone, in B6C3F1 mice. Toxicol. Appl. Pharmacol., 124:131-138, 1994.

[15] Hon-Wing Leung, Alan Poland, Dennis J. Paustenbach, F. Jay Murray, and Melvin E. Andersen. Pharmacokinetics of [125I]-2-Iodo-3,7,8-trichlorobenzo-p-dioxin in mice: Analysis with a physiological modeling approach. Toxicol. Appl. Pharmacol., 103:411419, 1990. 
[16] Andrew B. Lindstrom, Karen Yeowell-O'Connell, Suramya Waidyanatha, Bernard T. Golding, Rogelio Tornero-Velez, and Stephen M. Rappaport. Measurement of benzene oxide in the blood of rats following administration of benzene. Carcinogenesis, 18:16371641, 1997.

[17] Mark R. Lovern, M. Elizabeth Maris, and Paul M. Schlosser. Use of a mathematical model of rodent in vitro benzene metabolism to predict human in vitro metabolism data. Carcinogenesis, 20:1511-1520, August 1999.

[18] Laureen MacEachern, Robert Snyder, and Dabra Laskin. Alterations in the morphology and functional activity of bone marrow phagocytes following benzene treatment in mice. Toxicol. Appl. Pharmacol., 117:147-154, 1992.

[19] Guy M. Mainwaring, Sally M. Williams, John R. Foster, Jonathan Tugwood, and Trevor Green. The distribution of theta-class glutathione s-transferases in the liver and lung of mouse, rat and human. Biochem. J., 318:297-303, 1996.

[20] Casare Maltoni, Barbara Conti, Guiliano Cotti, and Fiorella Belpoggi. Experimental studies on benzene carcinogenicity at the Bologna institute of oncology: Current results and ongoing research. Am. J. Ind. Med., 7:415-446, 1985.

[21] Cesare Maltoni, Barbara Conti, and Giuliano Cotti. Benzene: a multipotential carcinogen. Results of long-term bioassays performed at the Bologna institute of oncology. Am. J. Ind. Med., 4:589-630, 1983.

[22] James M. Mathews, Amy S. Etheridge, and H.B. Matthews. Dose-dependent metabolism of benzene in hamsters, rats, and mice. Toxicol. Sci., 44:14-21, 1998.

[23] M. A. Medinsky, P. J. Sabourin, G. Lucier, L. S. Birnbaum, and R. F. Henderson. A physiological model for simulation of benzene metabolism in rats and mice. Toxicol. Appl. Pharmacol., 99:193-206, 1989.

[24] Michele A. Medinsky, Elaina Kenyon, Mark J. Seaton, and Paul M. Schlosser. Mechanistic considerations in benzene physiological model developement. Environ. Health Perspect., 104(Supplement 6):1399-1404, December 1996.

[25] Michele A. Medinsky, Elaina M. Kenyon, and Paul M. Schlosser. Benzene: a case study in parent chemical and metabolite interactions. Toxicology, 105:225-233, 1995.

[26] Michele A. Medinsky, Teresa L. Leavens, Gyorgy A. Csanady, Michael L. Gargas, and James A. Bond. In vivo metabolism of butadiene by mice and rats: a comparison of physiological model predictions and experimental data. Carcinogenesis, 15:1329-1340, 1994.

[27] Vessela Nedelcheva, Ivan Gut, Pavel Soucek, Bronislava Tichavska, Lucie Tynkova, Jaroslav Mraz, F. Peter Guengerich, and Magnus Indelman-Sundberg. Metabolism of benzene in human liver microsomes: individual variations in relation to CYP2E1 expression. Arch. Toxicol., 73:33-40, 1999. 
[28] D.V. Parke and R.T. Williams. Studies in detoxification: 49. The metabolism of benzene containing $\left[{ }^{14} C_{1}\right]$ benzene. J. Biochem., 54:231-238, 1953.

[29] Andrew Parkinson. Biotransformation of xenobiotics. In Curtis D. Klaassen, editor, Casarett and Doull's Toxicology: The Basic Science of Poisons, pages 113-186. McGraw-Hill, Inc., 5 edition, 1996.

[30] Patrick Poulin and Kannan Krishnan. An algorithm for predicting tissue:blood partition coefficients of organic chemicals from n-octanol:water partition coefficient data. $J$. Toxicol. Environ. Health, 46:117-129, 1995.

[31] Patrick Poulin and Kannan Krishnan. A biologically-based algorithm for predicting human tissue:blood partition coefficients of organic chemicals. Human Exp. Toxicol., 14:273-280, 1995.

[32] Clark Robinson. Dynamical Systems: Stability, Dynamics, and Chaos. CRC Press, Inc., 1995.

[33] Patrick J. Sabourin, William E. Bechtold, Linda S. Birnbaum, George Lucier, and Rogene F. Henderson. Differences in the metabolism and disposition of inhaled $\left[{ }^{3} H\right]$ benzene by $\mathrm{F} 344 / \mathrm{N}$ rats and $B 6 C 3 F_{1}$ mice. Toxicol. Appl. Pharmacol., 94:128-140, 1988.

[34] Patrick J. Sabourin, B. T. Chen, George Lucier, Linda S. Birnbaum, Ellen Fisher, and Rogene F. Henderson. Effect of dose on the absorption and excretion of $\left[{ }^{14} C\right]$ benzene administered orally or by inhalation in rats and mice. Toxicol. Appl. Pharmacol., 87:325$336,1987$.

[35] Mark J. Seaton, Paul M. Schlosser, and Michele A. Medinsky. In vitro conjugation of benzene metabolites by human liver: potential influence of interindividual variability on benzene toxicity. Carcinogenesis, 16:1519-1527, 1995.

[36] E.C. Steiner, T.D. Rey, and P.S. McCroskey. Simusolv Reference Guide. Dow Chemical Company, Midland, Michigan, 1990.

[37] Lance Wallace. Major sources of exposure to benzene and other volatile organic chemicals. Risk Anal., 10:59-64, 1990.

[38] A. Yardley-Jones, D. Anderson, and D.V. Parke. The toxicity of benzene and its metabolism and molecular pathology in human risk assessment. Br. J. Ind. Med., 48:437-444, 1991. 
Table 1: Parameter Values from Literature

\begin{tabular}{|c|c|c|c|}
\hline Parameter & Value & Unit & Source \\
\hline$B W$ & 0.030 & $\mathrm{~kg}$ & [23] \\
\hline$P_{B l: A i r}^{B Z}$ & 18 & & [23] \\
\hline$P_{F}^{B Z}$ & 28 & & {$[23]$} \\
\hline$P_{L}^{B Z}$ & 1 & & [23] \\
\hline$P_{S}^{B Z}$ & 0.6 & & [23] \\
\hline$P_{R}^{B Z}$ & 1 & & [23] \\
\hline$Q_{A v V}$ & $41 \mathrm{BW}$ & $\mathrm{L} / \mathrm{hr}$ & [26] \\
\hline$Q_{\text {Card }}$ & $Q_{A v V}$ & $\mathrm{~L} / \mathrm{hr}$ & [26] \\
\hline$Q_{L}$ & $0.25 Q_{\text {Card }}$ & $\mathrm{L} / \mathrm{hr}$ & {$[26]$} \\
\hline$Q_{F}$ & $0.09 Q_{\text {Card }}$ & $\mathrm{L} / \mathrm{hr}$ & {$[26]$} \\
\hline$Q_{K}$ & $0.146 Q_{\text {Card }}$ & $\mathrm{L} / \mathrm{hr}$ & {$[3]$} \\
\hline$Q_{S}$ & $0.15 Q_{\text {Card }}$ & $\mathrm{L} / \mathrm{hr}$ & [26] \\
\hline$Q_{R}$ & $0.51 Q_{\text {Card }}-Q_{K}$ & $\mathrm{~L} / \mathrm{hr}$ & [26] \\
\hline$V_{L}$ & $0.0624 \mathrm{BW}$ & $\mathrm{L}$ & {$[26]$} \\
\hline$V_{F}$ & $0.1 \mathrm{BW}$ & $\mathrm{L}$ & {$[26]$} \\
\hline$V_{K}$ & $0.015 \mathrm{BW}$ & $\mathrm{L}$ & {$[3]$} \\
\hline$V_{S}$ & $0.70 \mathrm{BW}$ & $\mathrm{L}$ & [26] \\
\hline$V_{R}$ & $0.0226 \mathrm{BW}-V_{K}$ & $\mathrm{~L}$ & {$[26]$} \\
\hline$V_{B l}$ & $0.05 \mathrm{BW}$ & $\mathrm{L}$ & {$[15]$} \\
\hline$C^{C P}$ & 82.8 & $\mathrm{mg} / \mathrm{g}$ liver & {$[26]$} \\
\hline$C^{M P}$ & 35 & $\mathrm{mg} / \mathrm{g}$ liver & {$[26]$} \\
\hline$K_{m, 1}^{P H}$ & 1.4 & $\mu \mathrm{mol} / \mathrm{L}$ & {$[35]$} \\
\hline$K_{m, 2}^{P H}$ & 220 & $\mu \mathrm{mol} / \mathrm{L}$ & {$[35]$} \\
\hline$K_{m}^{H Q}$ & 746 & $\mu \mathrm{mol} / \mathrm{L}$ & {$[35]$} \\
\hline$A^{B Z}$ & 0.0397 & $\mathrm{~L} / \mu \mathrm{mol}$ & {$[27]$} \\
\hline$A^{P H}$ & $1.30 \times 10^{-2}$ & $\mathrm{~L} / \mu \mathrm{mol}$ & {$[17]$} \\
\hline$A^{H Q}$ & $10^{-7}$ & $\mathrm{~L} / \mu \mathrm{mol}$ & {$[17]$} \\
\hline$k_{1}$ & $4.20 \times 10^{-5}$ & $\mathrm{~L} / \mathrm{nmol}$ & {$[17]$} \\
\hline$k_{2}$ & 32.16 & $1 / \mathrm{hr}$ & {$[17]$} \\
\hline$k_{5}$ & $4.00 \times 10^{-5}$ & $\mathrm{~L} / \mathrm{nmol}$ & {$[17]$} \\
\hline$k_{6}$ & $2.13 \times 10^{-6}$ & $\mathrm{~L} / \mathrm{nmol}$ & {$[17]$} \\
\hline$k_{7}$ & $2.03 \times 10^{-7}$ & $\mathrm{~L} / \mathrm{nmol}$ & {$[17]$} \\
\hline
\end{tabular}


Table 2: Partition Coefficients*

\begin{tabular}{cc}
\hline Parameter & Value \\
\hline$P_{F}^{P H}$ & 27.63 \\
$P_{L}^{P H}$ & 2.17 \\
$P_{S}^{P H}$ & 1.22 \\
$P_{R}^{P H}$ & 2.17 \\
$P_{F}^{H Q}$ & 4.06 \\
$P_{L}^{H Q}$ & 1.04 \\
$P_{S}^{H Q}$ & 0.94 \\
$P_{R}^{H Q}$ & 1.04 \\
\hline
\end{tabular}

* Estimated by method of Poulin and Krishnan [30].

Table 3: Estimated Parameters

\begin{tabular}{lc}
\hline Parameter & Model Results \\
\hline$k_{3}(1 / \mathrm{hr})$ & 24.2934 \\
$k_{4}(1 / \mathrm{hr})$ & 1.1756 \\
$k_{8}(1 / \mathrm{hr})$ & 7.2920 \\
$k_{9}(1 / \mathrm{hr})$ & 6.7955 \\
$k_{10}(1 / \mathrm{hr})$ & 6.4496 \\
$V_{2 E 1}(\mathrm{nmol} / \mathrm{mg} / \mathrm{hr})$ & 1150 \\
$V_{P H 1}(\mu \mathrm{mol} / \mathrm{mg} \operatorname{protein} / \mathrm{hr})$ & 1.5111 \\
$V_{P H 2}(\mu \mathrm{mol} / \mathrm{mg} \operatorname{protein} / \mathrm{hr})$ & 0.0404 \\
$V_{H Q}(\mu \mathrm{mol} / \mathrm{mg} \operatorname{protein} / \mathrm{hr})$ & 0.5186 \\
\hline
\end{tabular}


Table 4: Oral Dose (mg/kg-BW)

\begin{tabular}{|c|c|c|c|c|}
\hline $\begin{array}{l}\text { Oral } \\
\text { Dose }\end{array}$ & Amount & $\begin{array}{l}\text { Experimental } \\
\text { Data }(\mu \mathrm{mol})\end{array}$ & $\begin{array}{c}\text { SCL } \\
\text { Model } \\
\text { Results } \\
(\mu \mathrm{mol})\end{array}$ & $\begin{array}{c}\text { MCL } \\
\text { Model } \\
\text { Results } \\
(\mu \mathrm{mol})\end{array}$ \\
\hline \multirow[t]{4}{*}{0.1} & $\mathrm{MA}(\mathrm{t}=24 \mathrm{hrs})$ & $0.0328 \pm 0.0041^{*}$ & 0.0221 & 0.0274 \\
\hline & $\operatorname{PMA}(\mathrm{t}=24 \mathrm{hrs})$ & $0.0123 \pm 0.0034^{*}$ & 0.0092 & 0.0112 \\
\hline & PH Conj ( $\mathrm{t}=24$ hrs $)$ & $0.0574 \pm 0.0015^{*}$ & 0.1008 & 0.0811 \\
\hline & HQ Conj ( $\mathrm{t}=24 \mathrm{hrs})$ & $0.0746 \pm 0.0035^{*}$ & 0.1125 & 0.0363 \\
\hline \multirow[t]{2}{*}{1} & PH Conj ( $\mathrm{t}=48$ hrs) & $1.1598 \pm 0.0230^{\dagger}$ & 0.9180 & 0.8052 \\
\hline & HQ Conj ( $\mathrm{t}=48 \mathrm{hrs})$ & $1.6514 \pm 0.0307^{\dagger}$ & 1.1617 & 0.3626 \\
\hline \multirow[t]{2}{*}{10} & PH Conj ( $\mathrm{t}=48$ hrs) & $14.5557 \pm 0.4225^{\dagger}$ & 6.7854 & 6.6635 \\
\hline & HQ Conj ( $\mathrm{t}=48 \mathrm{hrs})$ & $13.8260 \pm 0.1536^{\dagger}$ & 10.2232 & 2.7385 \\
\hline \multirow[t]{4}{*}{100} & $\mathrm{MA}(\mathrm{t}=24 \mathrm{hrs})$ & $11.1718 \pm 1.5919^{*}$ & 11.2602 & 12.6762 \\
\hline & PMA $(\mathrm{t}=24 \mathrm{hrs})$ & $4.6803 \pm 1.5919^{*}$ & 4.6801 & 5.2551 \\
\hline & PH Conj ( $\mathrm{t}=24$ hrs) & $37.7096 \pm 1.6586^{*}$ & 32.9423 & 38.4504 \\
\hline & HQ Conj ( $\mathrm{t}=24 \mathrm{hrs})$ & $27.4339 \pm 1.9732^{*}$ & 56.4435 & 12.6435 \\
\hline
\end{tabular}

Table 5: 6-hour 50 ppm Inhalation Exposure

\begin{tabular}{lccc}
\hline $\begin{array}{c}\text { Concentration } \\
\text { at } \mathrm{t}=6 \text { hours }\end{array}$ & $\begin{array}{c}\text { Experimental } \\
\text { Data [33] } \\
(\mu \mathrm{mol} / \mathrm{L})\end{array}$ & $\begin{array}{c}\text { SCL } \\
\text { Model Results } \\
(\mu \mathrm{mol} / \mathrm{L})\end{array}$ & $\begin{array}{c}\text { MCL } \\
\text { Model Results } \\
(\mu \mathrm{mol} / \mathrm{L})\end{array}$ \\
\hline BZ in Liver & $4.5 \pm 0.9$ & 0.4900 & 4.4999 \\
PH in Liver & $0.3 \pm 0.1$ & 0.3000 & 0.1958 \\
HQ in Liver & $2.1 \pm 0.3$ & 0.5834 & 1.3206 \\
PH in Blood & $1.3 \pm 1.1$ & 0.0657 & 1.3000 \\
HQ in Blood & $4.3 \pm 4.0$ & 0.1207 & 1.2693 \\
\hline
\end{tabular}




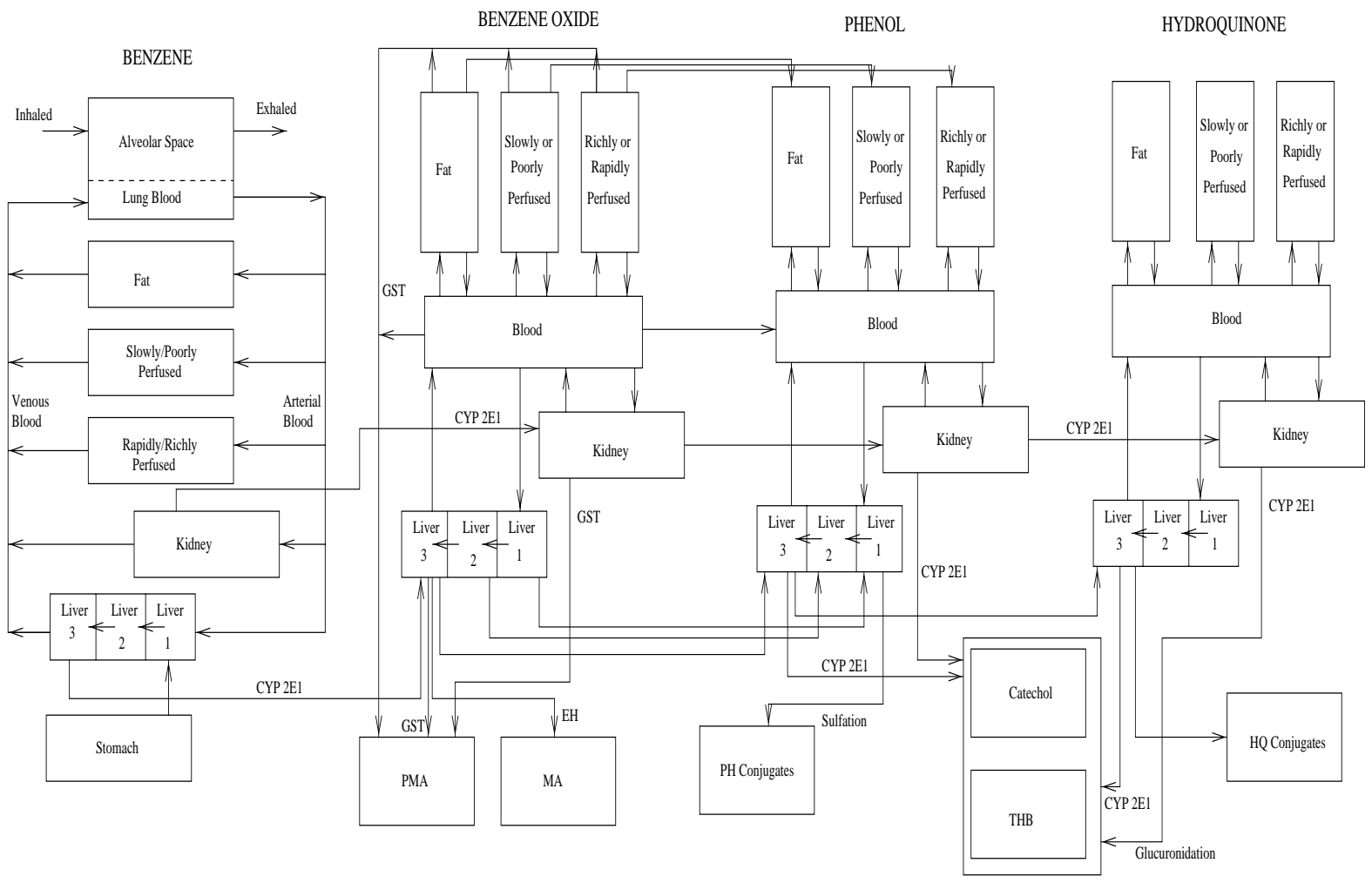

Figure 1: Schematic Representation of the Compartmental Model 

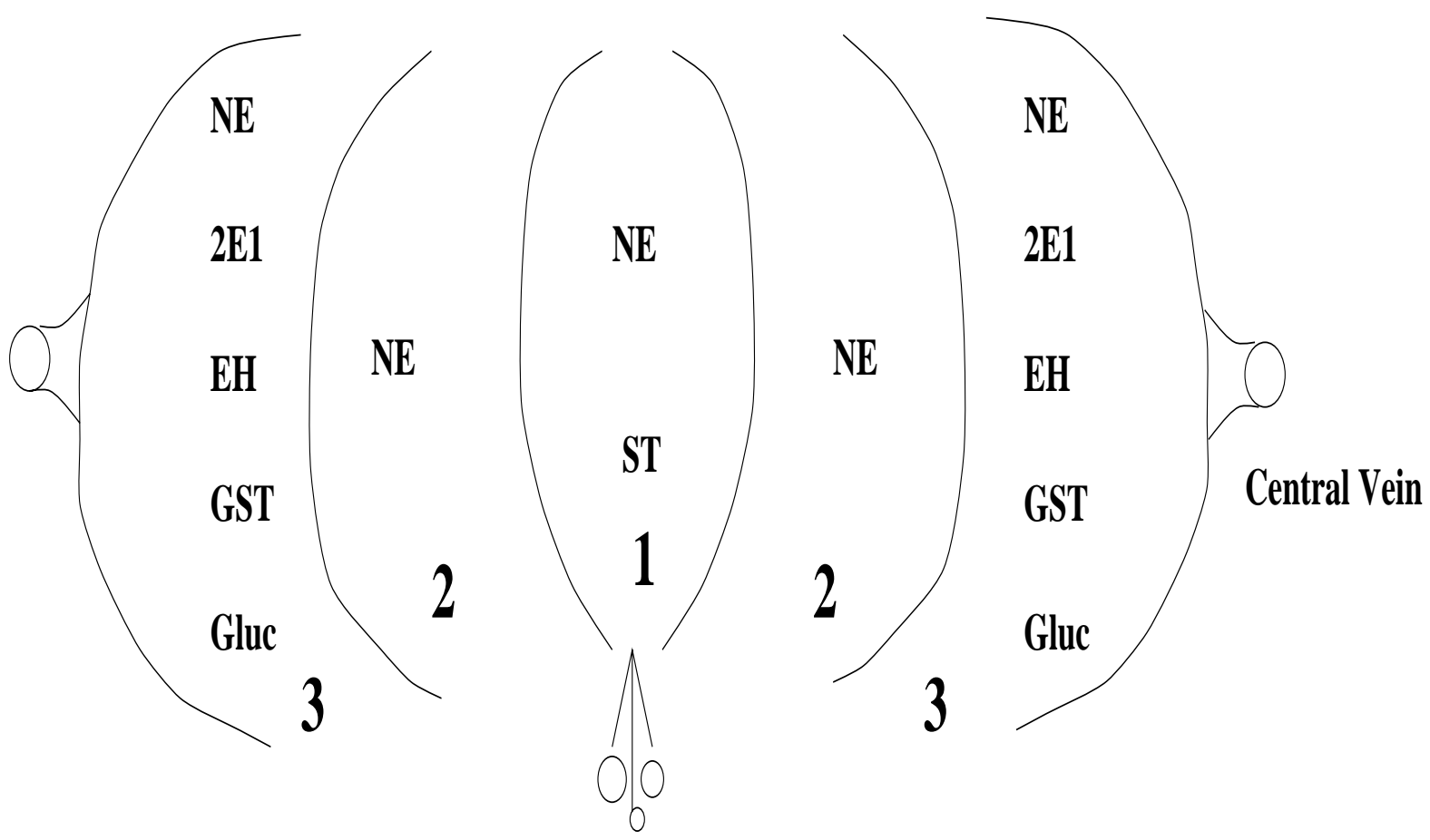

\section{Portal Triad}

Figure 2: Zonal Distribution of Enzymes in the Liver (NE=nonenzymatic, $\mathrm{ST}=$ sulfotransferase, 2E1=CYP2E1, EH=epoxide hydrolase, Gluc=gluronidation) $[19,29]$ 


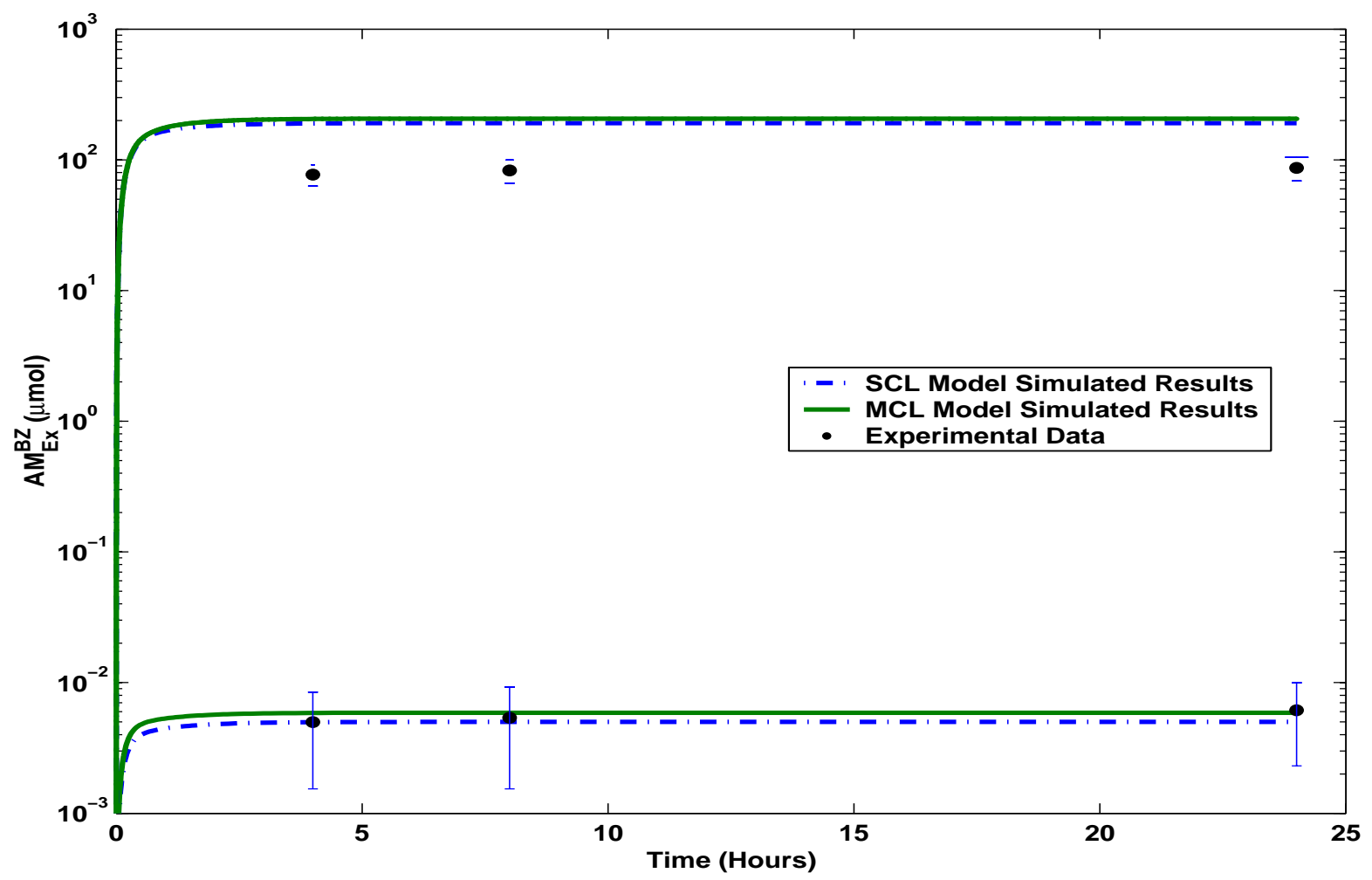

Figure 3: Time Course Data for Amount of Benzene Exhaled following Oral Dose [22]. (The bottom curves correspond to an initial dose of $0.1 \mathrm{mg} / \mathrm{kg}-\mathrm{BW}$ while the upper curves correspond to an initial dose of $100 \mathrm{mg} / \mathrm{kg}-\mathrm{BW}$ ) 


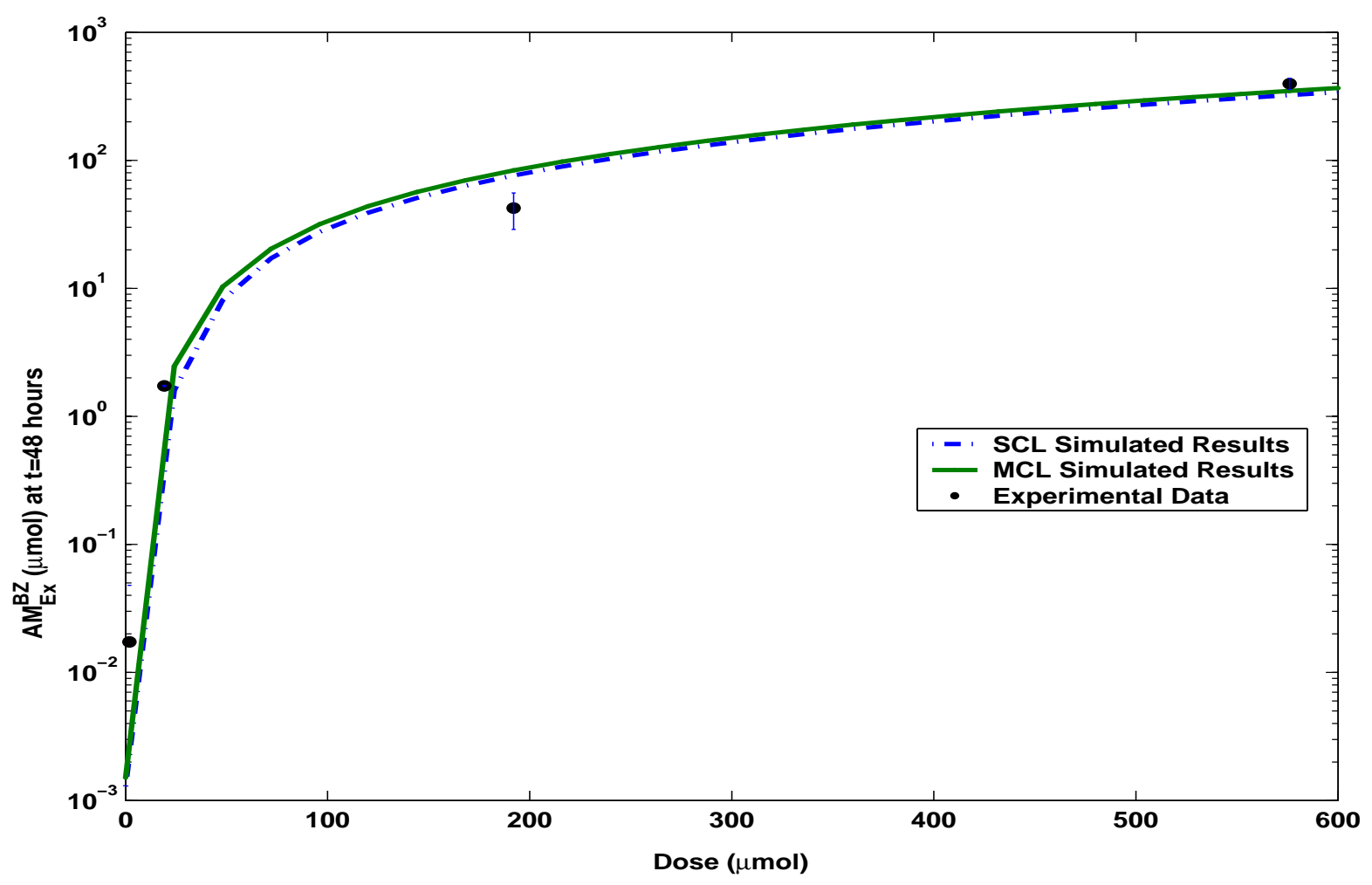

Figure 4: Amount of Benzene Exhaled at $\mathrm{t}=48$ hours following Oral Dose [34] 